UDC $539.43 ; 539.53+623.4$

\title{
REDUCTION IN STRESSED STATE OF STRENGTHENING COATINGS VIA USING A DISCRETE STRUCTURE OF ISLAND TYPE
}

\author{
Ye. Solovykh, $\mathrm{PhD}$ \\ Kirovohrad National Technical University \\ E-mail: eks_09@mail.ru
}

\begin{abstract}
The article is devoted to the development of the trend for creation of coatings with a discrete structure. The discrete structure of the island type is shown to provide operability of high-modulus superhard coatings on metals and alloys with lower elasticity modulus. Under contact loads, it reduces tensile stresses by over 3 times.
\end{abstract}

Keywords: coating, discrete structure of island type, stress, elasticity modulus, strength.

У статті подано розвиток напряму створення покриттів дискретної структури. Показано, що дискретна структура островкого типу дозволяе забезпечити прачездатність високомодульних надтвердих покриттів на металах $і$ сплавах з меншими значеннями модулів пружності. В умовах контактних навантажень дискретна структура островкового типу знижуе напруження розтягу більи, ніж в 3 рази.

Ключові слова: покриття, дискретна структура островкого типу, напруження, модуль пружності, міцність.

\section{Introduction}

Every method for deposition of protective coatings provides strengthening of working surfaces of parts and ultimate bearing capacity of the coating, which can be achieved through optimization of coating construction and process $\mu$ conditions.

In order to improve the quality of coatings, a novel principle for deposition of strengthening coatings with high thermomechanical properties has been developed at Pysarenko Institute for Problems of Strength NAS of Ukraine (IPS). It consists in replacing a conventional continuous layer with a discontinuous mosaic-discrete structure. Realization of this principle in fabrication of coatings has permitted an increase in their adhesion and corrosion stability thanks to restriction of maximal stresses in both coating layer and adhesion contact.

A discontinuous mosaic-discrete structure makes it possible to increase limit state of coating, namely: contact loads by several times; critical tensile deformation of the base by up to two orders of magnitude, and longevity by several times as compared to a continuous coating of the same thickness, composition and hardness. The work of IPS [1] may be considered to be the earliest of the researches devoted to the creation of discrete coatings with controlled stress-deformation state (SDS). Then NIAT (Moscow) joined these researches [2, 3] as well as Irkutsk [4] and Dagestan [5] Polytechnic Institutes, Germany Aerospace Center (Cologne) [6], and Zaporizhzhia Automobile Plant [7, 8]. After the USRR breakdown NIAT continues working in this trend by itself [8-11]. Today coatings with discrete structure are developed in Belarus [12], Ufa Aviation Institute [13], DVO RAS (Khabarovsk) [14], V.N.Bakul Institute for Superhard Metals NAS of Ukraine [15] and the
National Aviation University [10]. There have appeared publications on 3D discrete structure ("spot-textured coatings") in the far abroad $[10,15]$. Therefore this new trend has gained a global character.

It is worth mentioning that IPS plays the leading part in the area of coatings with a discrete structure. Theoretical, technological and practical grounds for discrete coatings have been considered in O. V. Tsyguliev's [9] and V.S. Antoniuk's [7] doctor dissertations as well as in a number of candidate dissertations. The works of IPS are distinguished by a system approach, that is, technological, calculation and experimental methods are concentrated "in the same hands".

\section{The tasks of the research}

The following tasks aimed at further successful development and application of discrete coatings have been executed by the author under Prof. Liashenko's leadership:

- technological provision for creation of a discrete structure with required configuration of its individual spots;

- determination of geometric parameters of discrete structure from the viewpoint of minimal locked-up and operation stresses;

- determination of optimal process conditions for deposition of discrete coatings.

As a result of the fulfillment of these tasks directed to investigation of constructive - technological methods for improvement of protective coating operability, a discrete structure of strengthening protective coatings (SPC) has been created.

Evaluation of stress-deformation state of discrete SPC. Traditionally, techniques for surface strengthening are selected on empirical grounds. This leads to reduction in the service life of coatings, 
which is limited by insufficient strength, adhesion detachment of coating, and cracking.

To improve the quality of coatings (wear resistance, strength, etc.), one should design them keeping in mind the achievement of minimal stressdeformation state (SDS) in both coating layer and zone of its adhesion contact with the base [10].

The analysis of SDS of continuous and discrete coatings by numerical methods [7-10] has established the fact of decreasing SDS, in particular tensile stresses $\sigma_{+}$, under contact loads in case of a discrete structure. Fig. 1 represents calculation schemes for a traditional continuous and a discrete (quasicontinuous) coatings. The latter was modeled using conditional cross sections of coating with a regular step of $2 h$. In both cases, the coating thicknesses $h$ and elastic properties of coatings were equal, other conditions being equal. Contact load $p$ of the hertz type was applied to spot $2 h$, equal to the size of individual discrete spot along the $X$-axis. Section 1 is parallel to the surface of adhesion base-coating bonding and located near the outer surface of coating. Section 2 is near the surface of adhesion bonding.

Let us compare stress $\sigma_{x}$ for cases "a" and "b" as well as for sections 1 and 2 in both cases. The calculations show that in section 1 compressive stresses in the discrete coating markedly decrease and do not exceed $35 \%$ of the maximal compressive stresses in the continuous coating. The tensile stresses in the dangerous section decrease by three times and their maximal value is below $5 \%$ of that of compressive stresses. In the discrete coating near the adhesion contact plane (section 2), stresses change the sign, that is, transform from tensile into compressive ones. Herein they do not overcome $25 \%$ of the maximal compressive stress value.

The results of modeling showed that under contact loads a discrete structure essentially unloads the coating. The most important effect of a discrete structure consists in repeatedly decreasing tensile stresses, which, it its turn, leads to decreasing brittleness of superhard high-modulus coatings. The Pysarenko-Liebediev criterion of strength uses the ratio of ultimate strengths under tension and compression as a measure of brittleness [10].

Fig. $1, b$ demonstrates an idealized calculation scheme, when the distance between the neighboring discrete spots is close to zero. In reality this scheme cannot be realized. In order to calculate SDS in a discrete structure, such geometric parameters as the distance between discrete spots, size and shape of the spots, thickness (or depth) of coating and the shape of spot ends should be taken into account. It is varying these parameters that controls and minimizes SDS under given external loads.

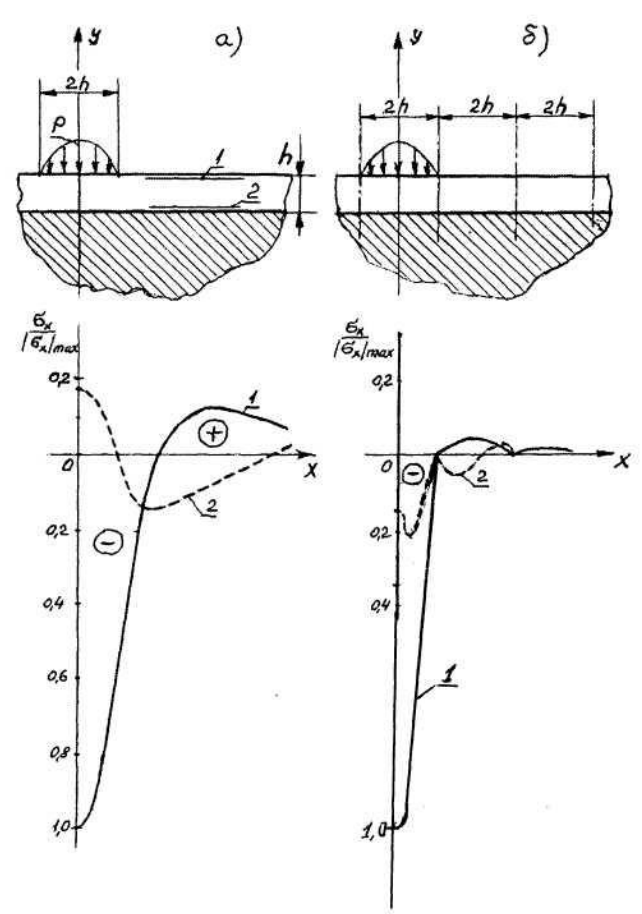

Fig. 1. Calculation scheme and distribution of stresses $\sigma_{x}$ under contact load $P$ : $a$ - continuous coating; $b$ - quasicontinuous (discrete) coating

In Fig. 2 the calculated values of the ratio of maximal tensile stresses $\sigma_{\max }^{+}$to maximal compressive stresses $\sigma_{\max }^{-}$are depicted along the $Y$-axis. Curves 1 and 2 refer to a continuous and a discrete coating and correspond to the calculation schemes "a" and " $\mathrm{b}$ " (Fig. 1), respectively, for the same contact load. Along the $X$-axis the ratio of the elastic modulus of the coating, $E_{n}$, to that of the base, $E_{o}$, is given, which models deposition of superhard high-modulus coatings on hard alloys, steels, Ti- and Al-alloys.

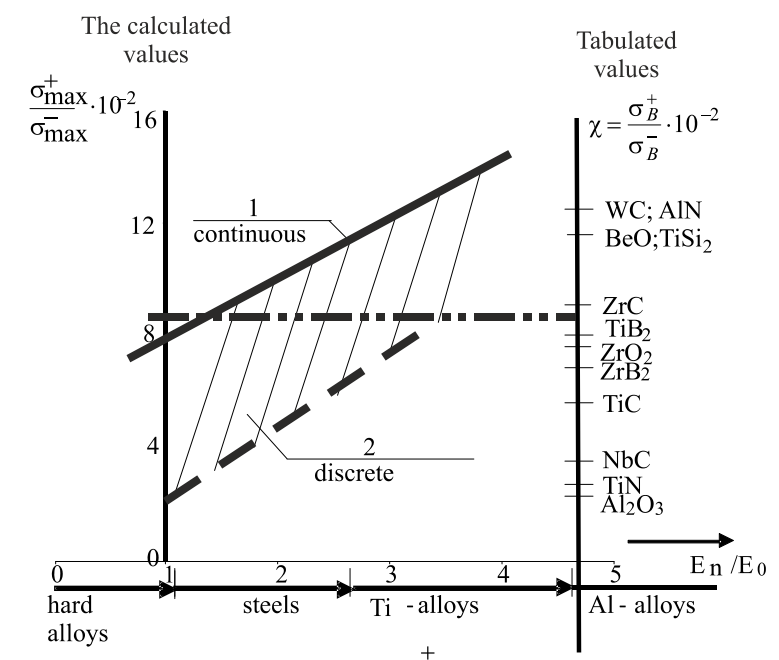

Fig. 2. The dependence of the $\sigma_{\max }^{+} / \sigma_{\max }^{-}$ratio on the elasticity modulus ratio $E_{\mathrm{\Pi}} / E_{\mathrm{o}}$ for (1) continuous and (2) discrete coatings. 
On the right, the ratios of ultimate strength under tension to ultimate strength under compression, $\chi$, are presented for a number of ceramic materials used for coatings [7; 9-15]. The value $\chi=0.07$ for $\mathrm{ZrO}_{2}$ is situated practically under curve 1 . This suggests that, according to the selected scheme, under contact loading in the continuous $\mathrm{ZrO}_{2}$ coating characterized by $E_{\mathrm{I}} / E_{\mathrm{o}}>0.8$, tensile stresses will appear reaching critical values. The discrete coating (curve 2) provides operability in this zone. This is consistent with the accumulated experience in application of superhard and brittle coatings on various constructive materials.

Before and today techniques for surface strengthening have been selected on empirical grounds, which results in reducing the service life of coating, limited by insufficient strength, adhesion detachment, and cracking.

The quality of coatings (wear resistance, strength, etc.) should be improved via rational design of them taking into account the achievement of minimal SDS in both coating layer and its adhesion contact with the base [6].

The sizes and configurations of individual spots of coating have been calculated on the basis of minimization of the level of SDS under mechanical and temperature actions on coating. Optimal sizes and configuration of discrete structure are determined using analytical and numerical methods taking into account the remaining technological stresses $[8,15]$.

To fabricate discrete coatings, one may use the same equipment as for traditional continuous coatings and make them from the same materials with the same thickness. A distinguish feature is the necessity in various shading and masking means.

Techniques based on using high-concentration sources of energy such as electric spark alloying and laser treatment are the most simple and available [3]. These technologies are discrete by nature, which allows one to use them without modernization of commercial equipment.

To produce strengthening protective coatings of discrete structure by various technologies, it is necessary to develop such methods and techniques that guarantee minimal expenses without reconstruction of commercial equipment. The PVD method seems to be promising for production of discrete coatings.

Let us consider in detail the vacuum plasma technology for discrete coatings, in particular the problem of loading a spot with a distributed normal contact load $q$ taking, as an example, vacuumplasma-derived discrete TiN coating $\left(E_{\text {п }}=4.4 \mathrm{GPa}\right)$ in the form of square with a side of $D=40 \mathrm{mcm}$ and thickness $h$. The thickness of coating varies within
2-16 mcm, the base is made from steel $6 \mathrm{KhVH}$ $\left(E_{\mathrm{o}}=2.3 \mathrm{GPa}\right)$ or hard alloy VC8 $\left(E_{\mathrm{o}}=7.2 \mathrm{GPa}\right)$. The SDS of the coating-base system was calculated using the finite element method in the license complex MSC VisualNastran for Windows [5]. The main aim of the calculations was to determine maximal values of stresses in any zone of coating (underlined by the author) as well as maximal stresses in the interface zone. Maximal stresses in the coating zone lead to cohesion cracking, whereas those in the interface zone cause adhesion detachment of coating. Maximal values of equivalent stress $\sigma_{3}$ were calculated according to the Pysarenko-Liebediev theory [10].

The SDS level depending on the discrete structure parameters may be presented in the form of the magnitude $\sigma_{\ni}$ relative to load $q$ or to ultimate strength under tension of coating $\sigma_{\hat{a}}^{+}$. The performed calculations revealed that maximal equivalent stresses in coating are observed at its ends, whereas those in the base are located in the central region. The dependence of the relative equivalent stresses $\sigma_{3} / q$ in the interface zone is of an extremal type (Fig. 3).

The wear resistance of coatings should be increased via rational design of them taking into account the achievement of minimal SPS inside both the coating and the zone of the coating-base contact [6].

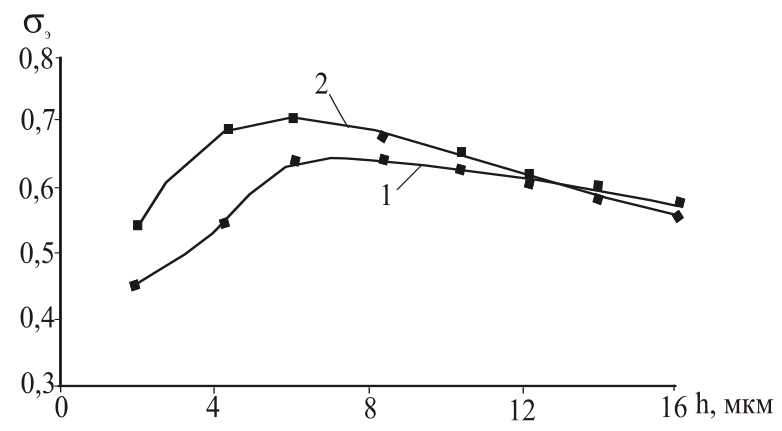

Fig. 3. The dependence of the equivalent stresses in the interface zone on the thickness of TiN coating on (1) VC8; (2) steel 6KhVH

For both bases, maximal equivalent stresses are observed at a thickness of $6-7 \mathrm{mcm}$. Herein equivalent stresses in the interface zone are greater for low-modulus base (steel) than for high-modulus hard alloys.

Along the ends of discrete spots, equivalent stresses near free surface of coating on a highmodulus base are bigger as compared to a lowmodulus base; with approaching the interface, they became smaller than those for a low-modulus base. The thicker a coating on a high-modulus base, the closer to the free surface the zone of action of maximal equivalent stresses moves from the interface (Fig. 4). 


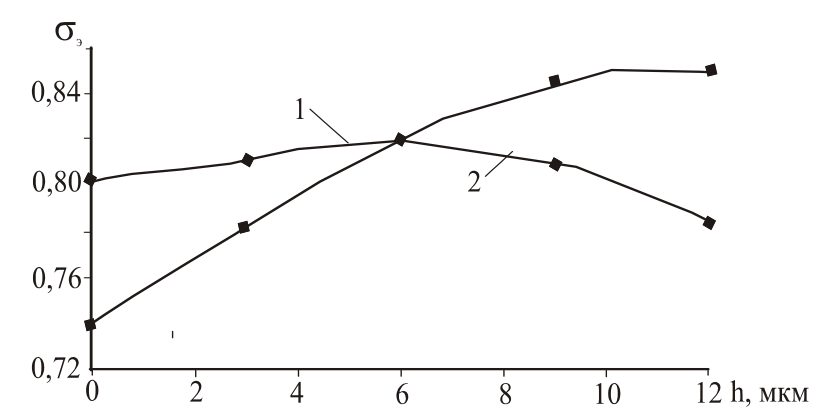

Fig. 4. Distribution of equivalent stresses through TiN coating on the base (1) VC8; (2) steel 6KhVH

The tangential stresses $\tau$ in the interface zone of coating on a high-modulus base are smaller that those on a low-modulus base (Fig. 5).

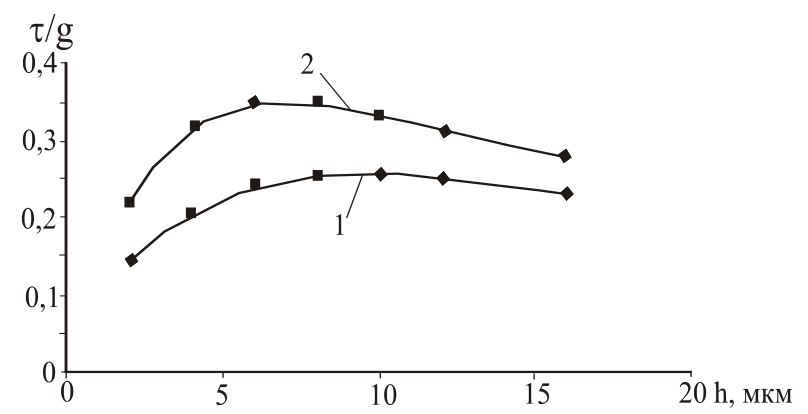

Fig. 5. Distribution of tangential stresses in the interface zone of TiN coating on (1) VC8; (2) steel 6KhVH

\section{Conclusions}

The obtained results permit one to draw the following conclusions:

1. Under contact loads, a discrete structure reduces tensile stresses $\sigma_{\max }^{+}$by over three times.

2. A discrete structure provides operability of high-modulus superhard coatings on metals and alloys with lower elasticity modulus.

3. On a low-modulus base, the prevailing mechanism of fracture is the detachment of coating along the ends under the action of tangential stresses (adhesion fracture) as well as plastic deformation of the base in the centers of discrete spots.

4. On a high-modulus base, with coating thickening, fracture which is initiated inside the coating is prevailing (cohesion fracture).

\section{References}

1. A. S. 677549 (SSSR), C 23 C 9/00, B23P 1/18. Method for deposition of coatings/ B. A. Liashenko, V. V. Rishin, E. S. Umanskii et al. - Published 30.07.79, Bul. N 28.

2. Novikov N. $V$. Methods for strengthening of machinery part surfaces / N. V. Novikov, A. A. Vidnyi, B. A. Liashenko et al. - K. : ISM AN USSR, 1989. - 112 p.
3. Liashenko B. A. Strengthening coatings of discrete structure/ B. A. Liashenko, A. Ya. Movshovich, A. I. Dolmatov/Tekhnological systems. - 2001. №4 (10). - P. 17-25.

4. Coatings and their engineering application. Book "Strength of materials and their constructions" ed. By V. T. Troshchenko. - Edition $2-$ K.: Akademperiodyka, 2006. - P. 981-1074.

5. $S N=1410876-075923$ 53bb492cfce94a.

6. Liashenko B. A. Increase in wear resistance of fitment using strengthening coatings/ B. A. Liashenko, M. V. Kindrachuk, Ye. B. Soroka, Ye. K. Solovykh, O. V. Gerasimova // Problems of friction and wear: Nauktechn. Zb. - K. : NAU, 2008. - Is. 49. - V. 1. P. 27-54.

7. Soroka Ye. B. Deflected mode of tool materials with vacuum plasma coatings / Ye. B. Soroka, V. S. Antoniuk, Ye. K. Solovykh et al. // Surface engineering and renovation of articles: Proceedings of VIII international science-engineering conference. May 27-29, 2008, Yalta-Kyiv : ATMU, 2008. - P. 223.

8. Klimenko S. A. Optimization of discrete structure in surface electric-contact hardening / S. A. Klimenko, Ye. K. Solovykh, Ye. B. Soroka et al. // Surface engineering and renovation of articles: Proceedings of VI International Science-Engineering Conference: May 30June 1, 2006, Yalta-Kyiv: ATMU, 2006. - P. 83-85.

9. Solovykh Ye. K. Decrease in brittleness of superhard coating via using discrete structure / Ye. K. Solovykh, O. V. Tsyguliev, Ye. B. Soroka // Current problems of production and maintenance in industry and transport: Proceedings of the 10-th Yub. International ScienceEngineering Seminar, February 2001, Svaliava. - K. : ATM Ukraine. - P. 217-219.

10. Pisarenko G. S. Deformation and strength of materials under complex stresses state / G. S. Pisarenko, A. A. Liebiediev. - K. : Nauk. dumka, 1976. - 515 p.

11. Samsonov G. V. Refractory coatings / G. V. Samsonov, A. P. Epik/ -M. :Metallurgiya, 1973. - 400 p.

12. Refractories for outer space. Reference book. M. : Metallurgiya, 1967. - $266 \mathrm{p}$.

13. New nonmetallic materials and coatings recommended for chemical engineering application. - M. : KHIMNEFTEMASH, 1977. - 74 p.

14. Frantsevich I. N. Elastic constants and elasticity moduli of metals and nonmetals. Ref. book/ I. N. Frantsevich, F. F. Voronov, S. A. Bakuma. - K. : Nauk. Dumka, 1982. - 287 p.

15. Liashenko B.A. Technological, constructive and operation peculiarities of discrete-structured strengthening coatings on machinery parts and tools / B. A. Liashenko, Ye. K. Solovykh, Ye. B. Soroka et al. // Proceedings of the XIII international science-engineering conference "Mechanical engineering and technosphere of the XXIst century". - Sevastopol, September 2006 Donetsk : DonNTU. - 2006, V. 4. - P. 292-296. 